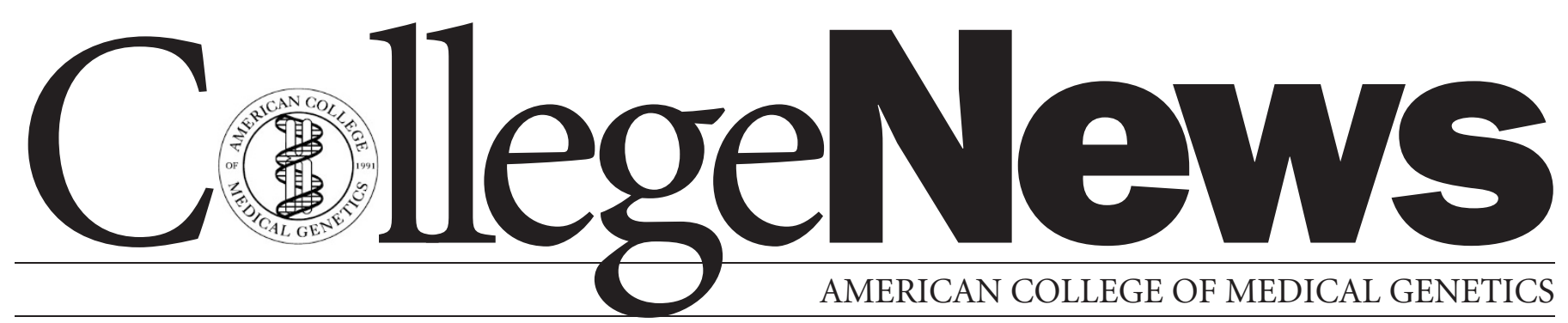

\title{
NEW TECHNICAL STANDARDS AND GUIDELINES NOW AVAILABLE ON-LINE.
}

The following Disease/Phenotype Standards and Guidelines are now available on the American College of Medical Genetics web site. These documents have been approved by the Board of Directors and are scheduled for publication in forthcoming issues of Genetics in Medicine.

- Technical Standards and Guidelines: Prenatal Screening for Down Syndrome http://www.acmg.net/Pages/ACMG_Activities/stds-2002/DS.htm

- Technical Standards and Guidelines for Open Neural Tube Defects http://www.acmg.net/Pages/ACMG_Activities/stds-2002/ONTD.htm

- Technical Standards and Guidelines for Venous Thromboembolism (Factor V Leiden and Prothrombin 20210G $>$ A Testing). http://www.acmg.net/Pages/ACMG_Activities/stds-2002/VT.htm

- In addition, a new subsection, E6: Chromosome Studies for Acquired Abnormalities can be found under Section E: Clinical Cytogenetics, of the ACMG Standards and Guidelines for Clinical Genetic Laboratories.

http://www.acmg.net/Pages/ACMG_Activities/stds-2002/e.htm 